\title{
Enhancement of voltage regulation using a 7-level inverter based electric spring with reduced number of switches
}

\author{
K. K. Deepika' ${ }^{1}$ J. Vijaya Kumar' ${ }^{2}$, G. Kesava Rao ${ }^{3}$ \\ ${ }^{1}$ Department of Electrical and Electronics Engineering, Vignan's Institute of Information Technology, India \\ ${ }^{1}$ KL Deemed to be University, India \\ ${ }^{2}$ Department of Electrical and Electronics Engineering, Anil Neerukonda Institute of Technology \& Science, India \\ ${ }^{3}$ Department of Electrical and Electronics Engineering, KL Deemed to be University, India
}

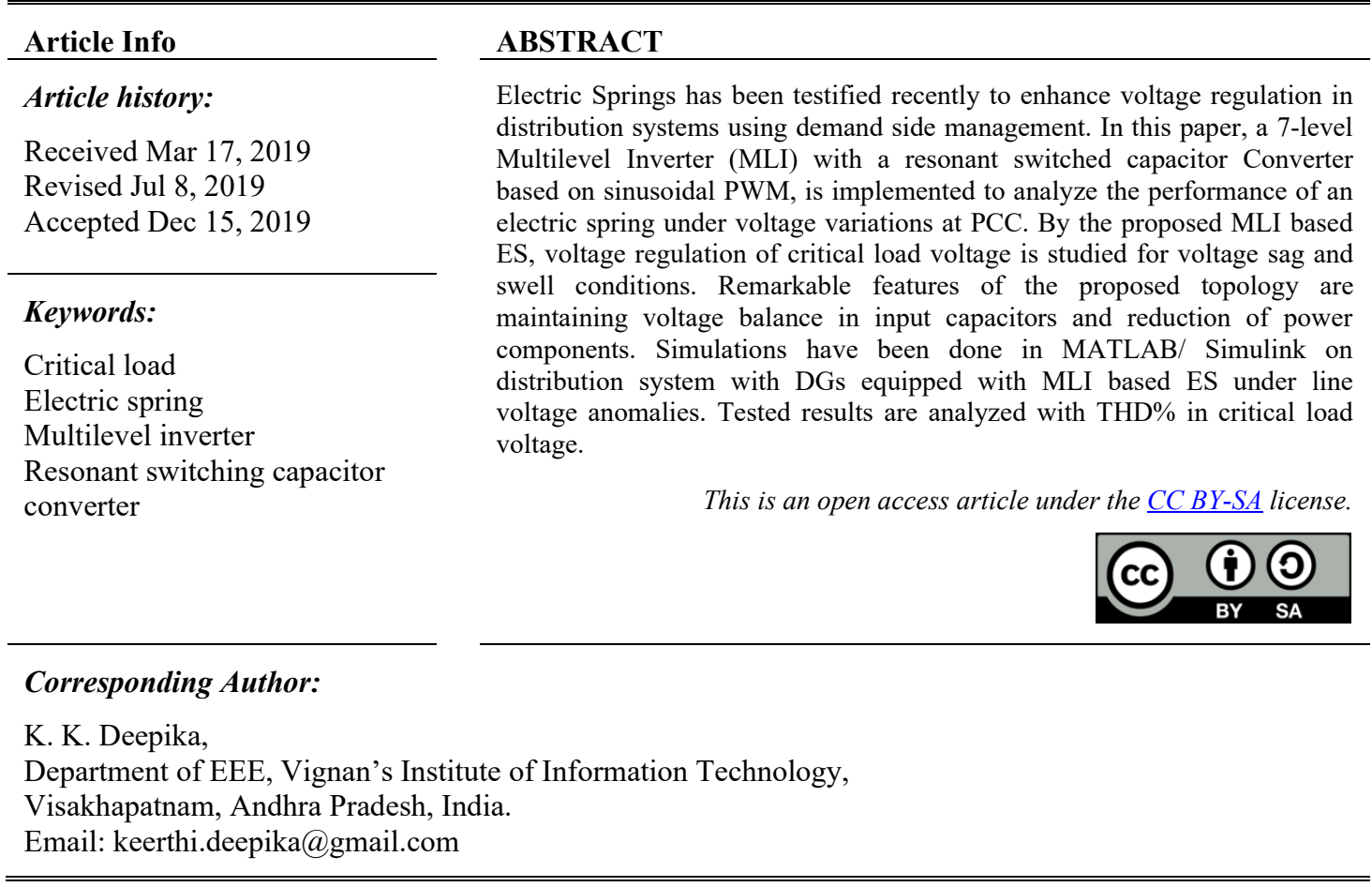

\section{INTRODUCTION}

Due to the high penetration of renewable sources of energy in distribution systems [1], voltage variations occur in the distribution system $[2,3]$. In this scenario, it is a challenging task to maintain constant voltage to hospital and military loads, known as critical loads as per their voltage sensitivity requirement [4]. Renewable energy sources also lead to the paradigm shift from centralized control to the distributed control in demand side management [5,6]. Electric Spring (ES) proposed in [7] by Hui et.al. when embedded in the less sensitive loads [8], is one of the simple ways to maintain constant voltage to the sensitive loads, without the need of any communication system $[9,10]$. ES regulates the input voltage while allowing fluctuations in load voltage [11]. Initial versions of ES implemented half-bridge inverters for this [12, 13], but suffered with high THD of $2.19 \%$. With the advent of multilevel inverters (MLI) in Power Electronics, they extend a great support to handle the intermittent renewable sources with increased power ratings and reduced THD [14]. Reducing the number of switches, THD and switching losses has always constituted a major area of research in Multilevel inverters [15, 16].

A 3-level Cascaded H-Bridge Inverter is implemented for ES control in [17]. Unlike the conventional MLI, it doesn't need a transformer. It is implemented in the distributed control of 4 Electric springs located at various locations in the distribution system. Simulations are carried out for inductive and capacitive modes of operation of ES, and results are discussed in terms of THD\%, RMS values of the mains voltages. 5-level Inverters in Diode-Clamped topology and Neutral Point Clamped inverter topology are 
implemented in ES control in [18, 19] respectively. They exhibit lesser THD\% across the critical loads when compared with the 3-level inverter control.

According to literature of failures in multilevel inverters, voltage unbalance has claimed the majority and is closely associated with stress in switching components. Voltage unbalance is also due to the type of connection made for the voltage division. Two major types of voltage unbalance problems are observed while the operation of MLI. They are midpoint unbalance and central capacitors discharge. Voltage unbalance leads to reduced output, consequently increasing the mechanical stress on the switches. This leads to poor performance of the loads and premature failure of components in inverter. Solutions to these are modulation schemes [20, 21], use of switched capacitor converters [22] and switched capacitors with resonant operation [23, 24]. Apart from the general discussion in terms of THD analyses, other solution methods as mentioned earlier are deliberated only in a few papers on MLI based ES. In [25], Inter-phase disposition Technique is implemented to control the active switches in the MLI.

In this paper, a 7-level Multilevel Inverter based ES is implemented. Voltage unbalance problem across the input capacitors in a MLI is analyzed and solved using a Resonant Switched Capacitor Converter based on sinusoidal PWM. The improvised topology is implemented to analyze the performance of an electric spring under line voltage variations. Remarkable features of the proposed topology are maintaining voltage balance in input capacitors and reduction of power components.

\section{OPERATING PRINCIPLE OF ES AND MLI}

Electric Spring is the new voltage compensating device employed in smart grids using demand side management. This custom power device is connected in series with a less voltage sensitive load like refrigerator, music system, etc. that have inbuilt Switched Mode Power Supply circuit to withstand voltage variations. This comprises a smart load. Smart load is connected across voltage sensitive load, termed as critical load, to maintain voltage constant. ES senses the voltage fluctuations in PCC and operates analogous to mechanical spring.

Operation of ES with half-bridge inverter, full bridge inverter, neutral point clamped inverter suffered from high THD, distortion in output voltage and higher stress on switches. MLI implemented in this paper is a 7-level inverter to overcome the drawbacks of the earlier mentioned topologies. Voltages obtained are $\frac{v_{d c}}{3}, 2 \frac{v_{d c}}{3}, v_{d c}, 0,-v_{d c},-2 \frac{v_{d c}}{3},-\frac{v_{d c}}{3}$. Another major benefit of realizing 7 - level output voltage with this topology is reduction in number of power switches. It is achieved with only 8 power switches in comparison with the 12 switches required with a cascaded multi-cell inverter, diode-clamped inverter, capacitor clamped inverter. Phase disposition technique is applied to generate 7 carrier triangular signals such that the bands they occupy are continuous and their frequency is about 300 times more than the reference signal. Reference signal is a sine wave of $50 \mathrm{~Hz}$ frequency generated by the controller of ES, as shown in Figure 1. Reference signal is continuously compared with each of the carrier waves to generate gate signals to the switches in the MLI. Figure 2 illustrates the single phase 7-level DC-AC converter with voltage balancing circuit and Table 1 presents the switching combinations required to generate the 7- level output voltage of the MLI. Figure 3 illustrates the comparison of the number of various components required in various type of inverters to obtain 7-level MLI output voltage.

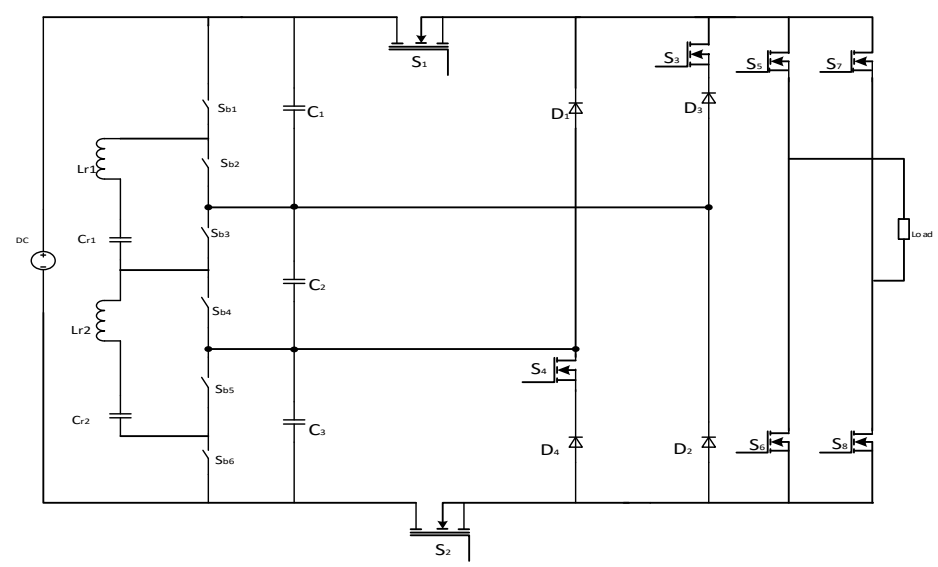

Figure 1. Simulated model of multilevel inverter with RSCC

Int J Pow Elec \& Dri Syst, Vol. 11, No. 2, June 2020 : 555 - 565 


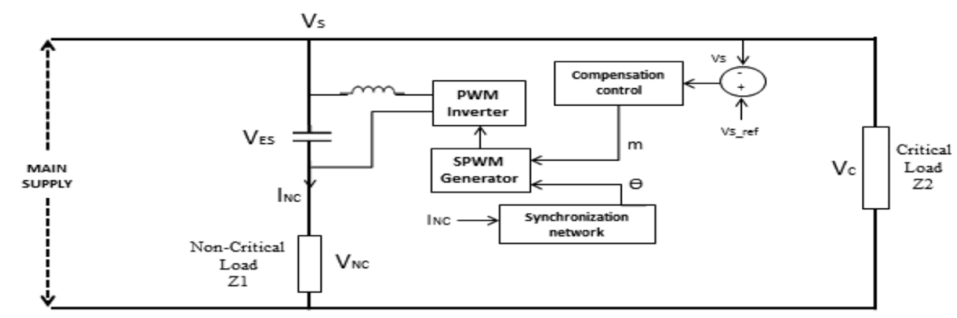

Figure 2. Schematic distribution system ES, MLI and resistive load

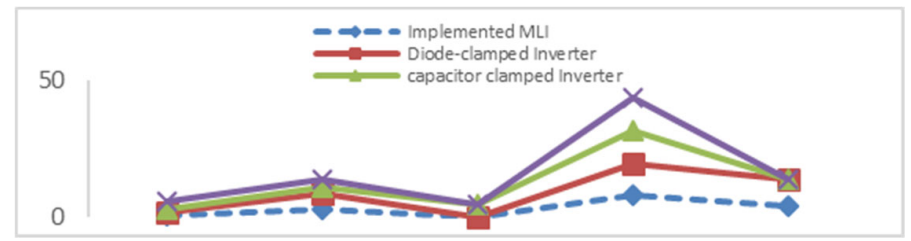

Figure 3. Comparison of components for 7-level inverter

Notations used in Figure 2 are:

$\mathrm{V}_{\mathrm{dc}}$

$\mathrm{S}_{\mathrm{b} 1}, \mathrm{~S}_{\mathrm{b} 2}, \mathrm{~S}_{\mathrm{b} 3}, \mathrm{~S}_{\mathrm{b} 4}, \mathrm{~S}_{\mathrm{b} 5}, \mathrm{~S}_{\mathrm{b} 6}$

$\mathrm{L}_{\mathrm{r} 1}, \mathrm{C}_{\mathrm{r} 1}$

$\mathrm{L}_{\mathrm{r} 2}, \mathrm{C}_{\mathrm{r} 2}$

$\mathrm{I}_{\mathrm{b} 1}, \mathrm{I}_{\mathrm{b} 2}$

$\mathrm{I}_{\mathrm{n} 1}, \mathrm{I}_{\mathrm{n} 2}$

$V c_{1}, V c_{2}, V c_{3}$
: input DC voltage

: Bridge switches

: resonant elements for RSCC 1

: resonant elements for RSCC 2

: bridge currents

: node currents

: capacitor voltages

$$
V c_{1}=V c_{2}=V c_{3}=\mathrm{V}_{\mathrm{dc}} / 3
$$

For the simulated Multilevel Inverter with RSCC as shown in the Figure 2, the switching table is detailed in Table 1. To obtain the 7 levels of output voltages, states of the switches constituting RSCC- $\mathrm{S}_{\mathrm{b} 1}$, $\mathrm{S}_{\mathrm{b} 2}, \mathrm{~S}_{\mathrm{b} 3}, \mathrm{~S}_{\mathrm{b} 4}, \mathrm{~S}_{\mathrm{b} 5}, \mathrm{~S}_{\mathrm{b} 6}$ and the MOSFETs, diodes in MLI are illustrated in Table 1.

Table 1. Switching Table for Multilevel Inverter with RSCC

\begin{tabular}{ccccccccccccccccccc}
\hline Switch Level & $\mathrm{S}_{\mathrm{b} 1}$ & $\mathrm{~S}_{\mathrm{b} 2}$ & $\mathrm{~S}_{\mathrm{b} 3}$ & $\mathrm{~S}_{\mathrm{b} 4}$ & $\mathrm{~S}_{\mathrm{b} 5}$ & $\mathrm{~S}_{\mathrm{b} 6}$ & $S_{1}$ & $S_{2}$ & $S_{3}$ & $S_{4}$ & $S_{5}$ & $S_{6}$ & $S_{7}$ & $S_{8}$ & $D_{1}$ & $D_{2}$ & $D_{3}$ & $D_{4}$ \\
\hline$\frac{V_{d c}}{\mathbf{3}}$ & 1 & 0 & 1 & 0 & 0 & 0 & 1 & 0 & 0 & 0 & 1 & 0 & 0 & 1 & 0 & 1 & 0 & 0 \\
$\frac{2 V_{d c}}{\mathbf{3}}$ & 1 & 0 & 0 & 0 & 1 & 0 & 1 & 0 & 0 & 1 & 1 & 0 & 0 & 1 & 0 & 0 & 0 & 1 \\
$V_{d c}$ & 1 & 0 & 0 & 0 & 0 & 1 & 1 & 1 & 0 & 0 & 1 & 0 & 0 & 1 & 0 & 0 & 0 & 0 \\
0 & 0 & 1 & 1 & 1 & 1 & 0 & 0 & 0 & 0 & 0 & 0 & 1 & 0 & 1 & 0 & 0 & 0 & 0 \\
$-\frac{V_{d c}}{\mathbf{3}}$ & 0 & 0 & 0 & 1 & 0 & 1 & 0 & 1 & 0 & 0 & 0 & 1 & 1 & 0 & 1 & 0 & 0 & 0 \\
$-\frac{2 V_{d c}}{\mathbf{3}}$ & 0 & 1 & 0 & 0 & 0 & 1 & 0 & 1 & 1 & 0 & 0 & 1 & 1 & 0 & 0 & 0 & 1 & 0 \\
$-V_{d c}$ & 1 & 0 & 0 & 0 & 0 & 1 & 1 & 1 & 0 & 0 & 0 & 1 & 1 & 0 & 0 & 0 & 0 & 0 \\
\hline
\end{tabular}

For voltage level $\frac{V d c}{3}$ :

$\mathrm{S}_{\mathrm{b} 1}$ and $\mathrm{S}_{\mathrm{b} 3}$ of RSCC-1 are in ON position and the current flows through capacitor $\mathrm{C}_{1}$ and it gets charged. The capacitor $C_{1}$ gets discharged through switches $S_{1}, S_{5}$ and its return path is through $S_{8}$ and $D_{1}$.

For voltage level $2 \frac{V d c}{3}$ :

$\mathrm{S}_{\mathrm{b} 1}$ and $\mathrm{S}_{\mathrm{b} 5}$ of RSCC -1 and RSCC -2 respectively are $\mathrm{ON}$ and hence capacitor $\mathrm{C}_{1}$ and $\mathrm{C}_{2}$ are charged. The capacitors get discharged in forward path of $\mathrm{S}_{1}, \mathrm{~S}_{5}$ and load, return path through $\mathrm{S}_{4}$ and $\mathrm{D}_{4}$. 
For voltage level $V_{d c}$ :

Switches $\mathrm{S}_{\mathrm{b} 1}$ and $\mathrm{S}_{\mathrm{b} 6}$ of RSCC-1 and RSCC-2 are in ON position and charges all the $\mathrm{C}_{1}, \mathrm{C}_{2}, \mathrm{C}_{3}$. They will discharge through switches $\mathrm{S}_{1}$ and $\mathrm{S}_{5}$ and the return path through $S_{8}$ and $S_{2}$. Since all the capacitors are discharging. So, the output voltages are $\frac{V_{d c}}{3}+\frac{V_{d c}}{3}+\frac{V_{d c}}{3}=V_{d c}$

\section{For voltage level $-\frac{V d c}{3}$ :}

Switches $\mathrm{S}_{\mathrm{b} 1}$ and $\mathrm{S}_{\mathrm{b} 6}$ are in conducting mode and $\mathrm{C}_{3}$ gets charged. It gets discharged through $\mathrm{D}_{1}$ and $\mathrm{S}_{7}$ in forward path and through load and $\mathrm{S}_{2}, \mathrm{~S}_{6}$ is the return path. The current direction through the load changes and hence the voltage is $-\frac{V_{d c}}{3}$.

For voltage level $-2 \frac{V d c}{3}$ :

Switches $\mathrm{S}_{\mathrm{b} 2}$ and $\mathrm{S}_{\mathrm{b} 6}$ of RSCC-1 and RSCC-2 respectively are in operating mode and the capacitors $\mathrm{C}_{2}, \mathrm{C}_{3}$ gets discharged. They discharge through the path $\mathrm{D}_{3}, \mathrm{~S}_{3}$ and $\mathrm{S}_{7}$ in the forward direction and $S_{6}, S_{2}$ are in return direction.

For voltage level $-V_{d c}$ :

Switches $\mathrm{S}_{\mathrm{b} 1}$ and $\mathrm{S}_{\mathrm{b} 6}$ are in $\mathrm{ON}$ position and the capacitors $\mathrm{C}_{1}, \mathrm{C}_{2}, \mathrm{C}_{3}$ gets charged. The capacitors will discharge through $S_{1}$ and $S_{7}$ in forward path $S_{2}$ and $S_{6}$ in return path.

\section{For voltage level zero:}

Switches $\mathrm{S}_{\mathrm{b} 2}, \mathrm{~S}_{\mathrm{b} 3}, \mathrm{~S}_{\mathrm{b} 4}, \mathrm{~S}_{\mathrm{b} 5}$ are short circuit and RSCC-1 and RSCC-2 are in working mode. There is no current flow through any of the capacitor hence charging or discharging. Due to the gate pulses given to switches $\mathrm{S}_{5}$ and $\mathrm{S}_{7}$ of MLI are in ON position and the current flows through the load.

In this paper, problem of voltage unbalance in input capacitors is overcome by using a voltage balancing circuit called Resonant Switching Capacitor Converter (RSCC) as shown in Figure 4. Based on the voltage level of multilevel inverter, the topology of RSCC changes. RSCC circuit implemented in this paper has seven modes of operation when compared with the conventional RSCC which has only two modes. It is realized to achieve balance of voltages among the input capacitors connected in series. Thus, voltage balance of input capacitors is achieved.

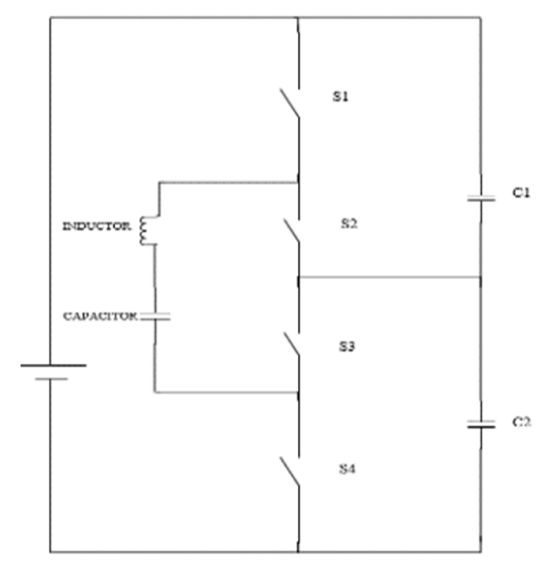

Figure 4. Conventional RSCC circuit

The voltage balance circuit transfers electric charge between the capacitor modules with a soft switching operation which results in reduced power loss and electromagnetic induction. A phase shifting control method enables to improve voltage regulation performance. It reduces power loss and electromagnetic induction. The main difference between switching capacitor converter and resonant switching capacitor converter is that in RSCC, there is an additional small inductor to achieve a soft switching or resonant operation. RSCC enables change of direction of power flow from higher to lower voltage by using fixed periodic gate signal. It consists of 6 switching devices - $S b_{1}, S b_{2}, S b_{3}, S b_{4}, S b_{5}, S b_{6}$ and 4

Int J Pow Elec \& Dri Syst, Vol. 11, No. 2, June 2020 : 555 - 565 
resonant circuit elements- $L r_{1}, C r_{1}, L r_{2}, C r_{2}$. This configuration suppresses spike currents and power losses and electromagnetic induction. Different modes of operation of RSCC will lead to different levels of voltages with an efficient way of voltage balancing across the capacitors. Two modes are explained below:

\section{Mode-1:}

In this mode, RSCC operates as follows to obtain a voltage of $\frac{V_{d c}}{3}$. Switches $\mathrm{S}_{\mathrm{b} 1}, \mathrm{Sb}_{2}$ are in closed condition, and current will flow in the resonant circuit of RSCC 1, as shown in Figure 5.

$$
I r_{1}=I b_{1}
$$

Applying KVL to Figure 3, we get

$$
\begin{aligned}
& L r_{1} \frac{d i r_{1}}{d t}+V c_{r 1}-V c_{1}=0 \\
& L r_{1} \frac{d i r_{1}}{d t}+V c_{r 1}=V c_{1}
\end{aligned}
$$

From (1) $V c_{1}=V_{\frac{d c}{3}}$

$$
V_{\frac{d c}{3}}=L r_{1} \frac{d i r_{1}}{d t}+V c_{r 1}
$$

\section{Mode -7:}

In this mode of operation, negative voltage peak of $-\mathrm{V}_{\mathrm{dc}}$ is obtained. Switching diagram is as shown in Figure 6. Switches $\mathrm{S}_{\mathrm{b} 6}$ and $\mathrm{S}_{\mathrm{b} 1}$ are $\mathrm{ON}$ position and the current will flow through both RSCC -1 and RSCC-2.

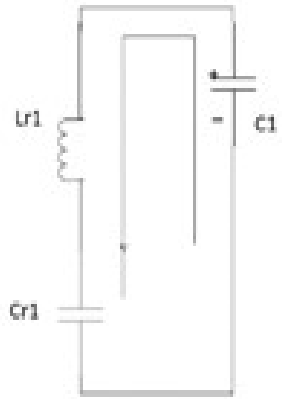

Figure 5. Operation of RSCC in mode 1

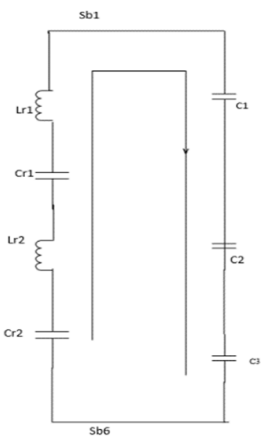

Figure 6. Operation of RSCC in mode 6

$$
I r_{1}=I r_{2}
$$

Applying KVL in Figure 6, we get

$$
\begin{aligned}
& L r_{1} \frac{d i r_{1}}{d t}+V c_{r 1}+L r_{2} \frac{d i r_{2}}{d t}+V c r_{2}+V c_{1}+V c_{2}+V c_{3}=0 \\
& L r_{1} \frac{d i r_{1}}{d t}+V c_{r 1}+L r_{2} \frac{d i r_{2}}{d t}+V c r_{2}=-\left(V c_{1}+V c_{2}+V c_{3}\right)
\end{aligned}
$$

From (1)

$$
L r_{1} \frac{d i r_{1}}{d t}+V c_{r 1}+L r_{2} \frac{d i r_{2}}{d t}+V c r_{2}=-V_{d c}
$$

From (5), we get

$$
V c_{r 1}+\frac{d i r_{2}}{d t}\left(L r_{1}+L r_{2}\right)+V c r_{2}=-V_{d c}
$$




\section{RESULTS AND ANALYSIS}

To analyze the operation of ES with MLI in neutral, undervoltage and overvoltage conditions, simulations are carried out in MATLAB 2011. To keep the analysis simple, critical and non-critical loads are selected to be resistive. Specifications of the distribution line, ES and loads is detailed in Table 2. The overall analysis can be divided into 3 parts: i) Undervoltage by $20 \%$ from 0.5 to $1 \mathrm{sec}$. ii) Overvoltage by $20 \%$ from 1.5 to $2 \mathrm{sec}$. iii) Neutral during remaining time. The main objective is to certify the operation of MLI in all the modes of ES. This is demonstrated in terms of THD analysis and the voltage balancing achieved in the input capacitors. Input voltage to the MLI is $400 \mathrm{~V}$ DC and the output voltage is $220 \mathrm{~V}$ RMS. The 7 voltage levels obtained are $\pm 133 \mathrm{~V}, \pm 267 \mathrm{~V}, \pm 400 \mathrm{~V}, 0 \mathrm{~V}$. The block diagram of the overall test system shown in Figure 7.

Table 2. System Specifications

\begin{tabular}{lllll}
\hline \multicolumn{2}{l}{ Specifications of Distribution Line, Non-critical load unit } & \multicolumn{3}{c}{ Specifications of Electric Spring } \\
\hline Line Inductance $(\mathrm{mH} / \mathrm{km})$ & 1.22 & Low-pass filter & Inductance $(\mathrm{mH})$ & 5 \\
Line Resistance $(\Omega / \mathrm{km})$ & 0.1 & Capacitance $(\mu \mathrm{F})$ & 13.2 \\
Non- critical Load $(\Omega)$ & 50.5 & PI Controller & $\mathrm{K}_{\mathrm{p}}$ & 2 \\
Critical load Z $(\Omega)$ & 53 & (Initial values) & $\mathrm{K}_{\mathrm{i}}$ & 1.5 \\
\hline
\end{tabular}

With the variations in the real power fed into the system by the DGs, voltage levels are affected. Results are shown for the simulation carried out for 1.5 seconds, in which due to real power fed by the DGs is changed from $1.8 \mathrm{KW}$ to $1.1 \mathrm{KW}$ at $0.5 \mathrm{sec}$ and then back to $1.8 \mathrm{KW}$ at $1 \mathrm{sec}$. This is traced with the RMS value of critical load voltage without ES control highlighted in Figure 8 and Figure 9. Critical load requires to be operated at 220 volts, but it falls to 185 volts.

Controller of the ES detects the undervoltage and operates to regulate the line voltage to $220 \mathrm{~V}$. Figure 10 and Figure 11 highlights that ES operates in about $0.08 \mathrm{sec}$ and restores the line voltage to rated value. RMS Voltage across ES is illustrated in Figure 12. As the voltage gets compensated there will be no effect of ES on the system from $1 \mathrm{sec}$. At $\mathrm{t}=1 \mathrm{sec}$, power fed by DGs is restored to normal. Due to the sudden change in the operation of filter capacitor component in ES, voltage spike occurs in Figure 13.

To validate the proposed topology further, real power fed by the DGs is changed from $1.8 \mathrm{KW}$ to $2.5 \mathrm{KW}$ at $1.5 \mathrm{sec}$ and then back to $1.8 \mathrm{KW}$ at $2 \mathrm{sec}$. It can be observed at Figure 14 that this leads to a voltage swell condition in the line. In swell condition the voltage increases to greater than the reference voltage at $\mathrm{t}=1.5 \mathrm{secs}$. So, ES reduces the voltage dip and regulates the line voltage of the system.

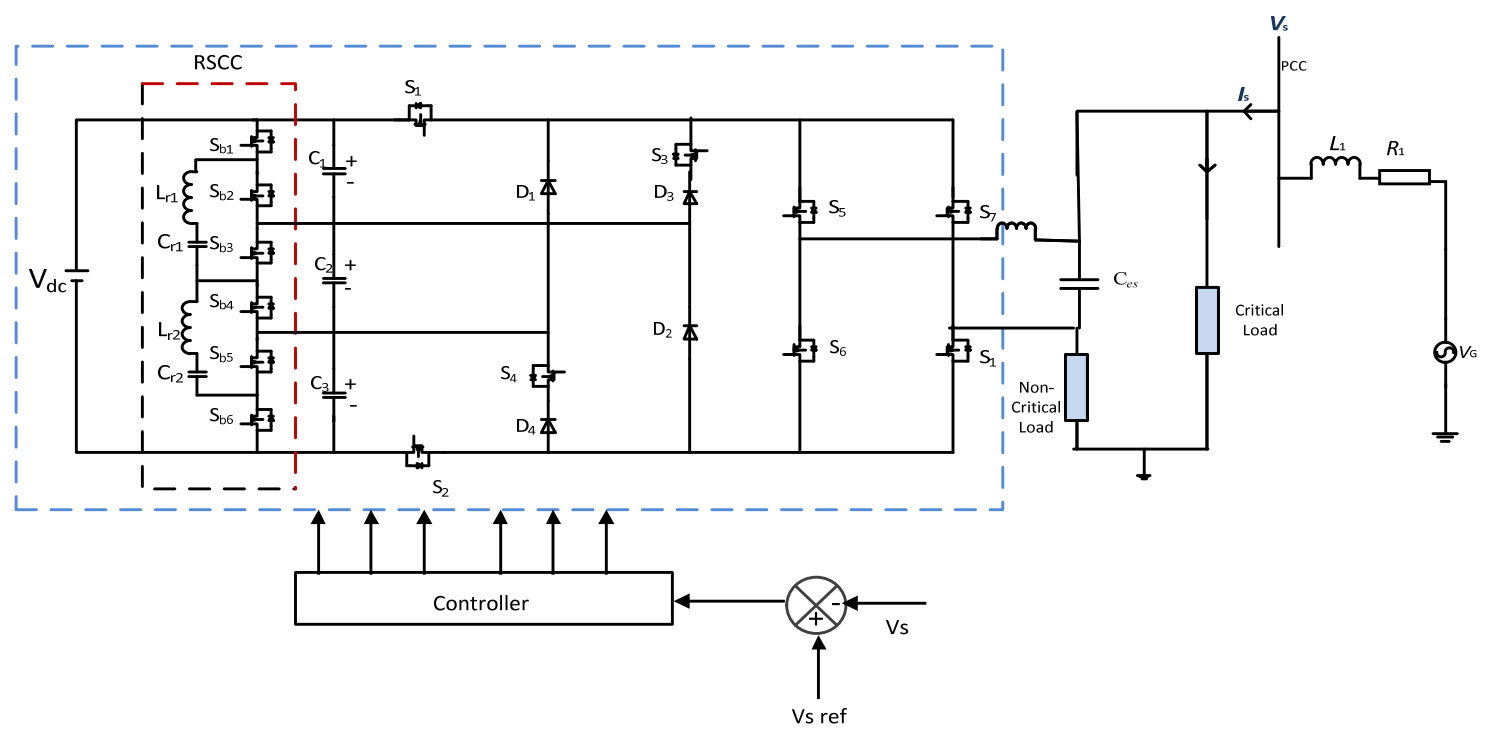

Figure 7. Block diagram of the overall test system

Int J Pow Elec \& Dri Syst, Vol. 11, No. 2, June 2020 : 555 - 565 


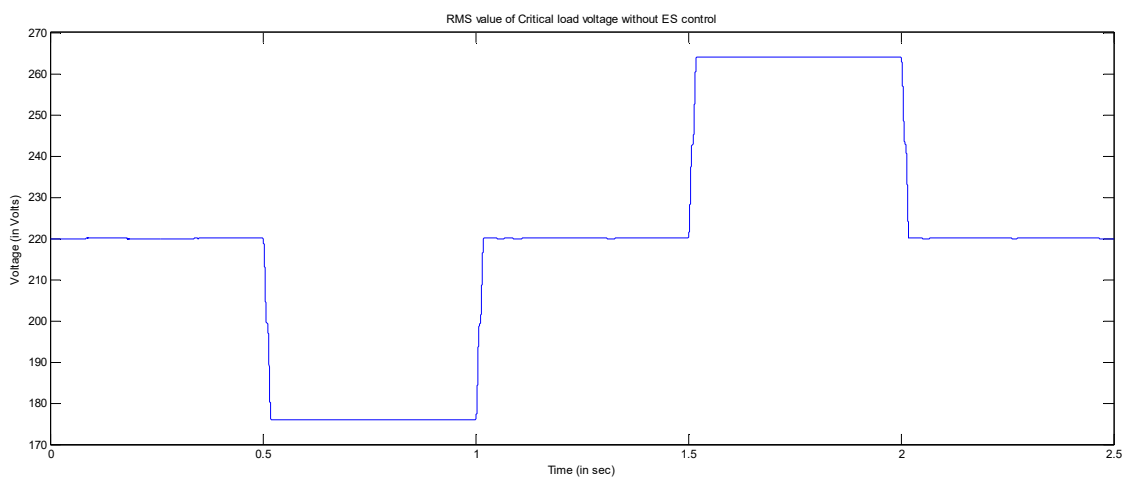

Figure 8. RMS value of critical load voltage, without ES control

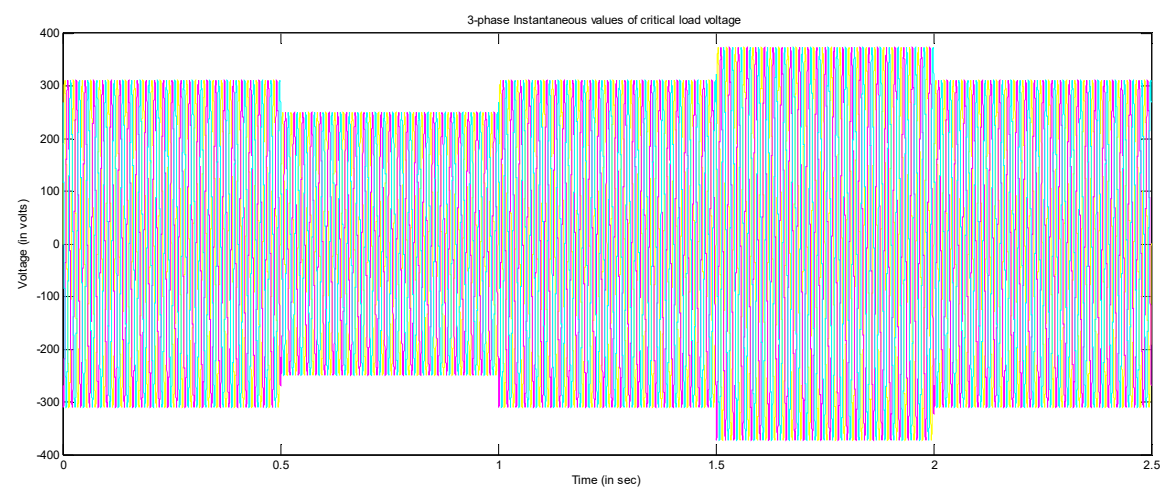

Figure 9. Instantaneous value of critical load voltage, without ES control

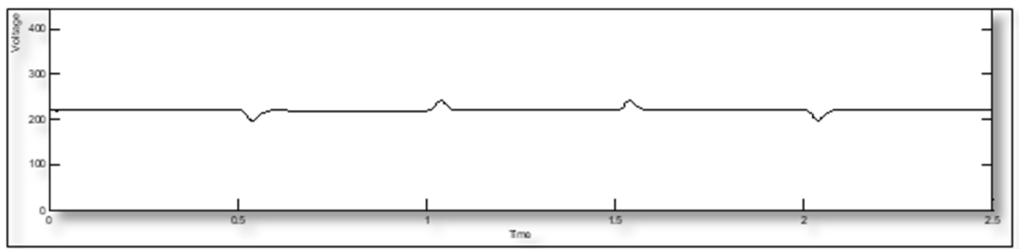

Figure 10. RMS value of critical load voltage with ES control

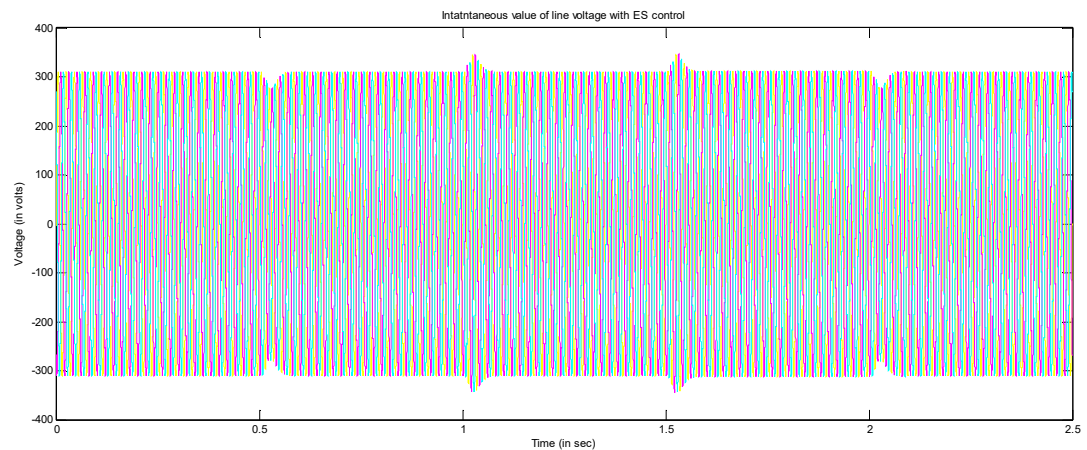

Figure 11. Instantaneous value of critical load voltage, with ES control 


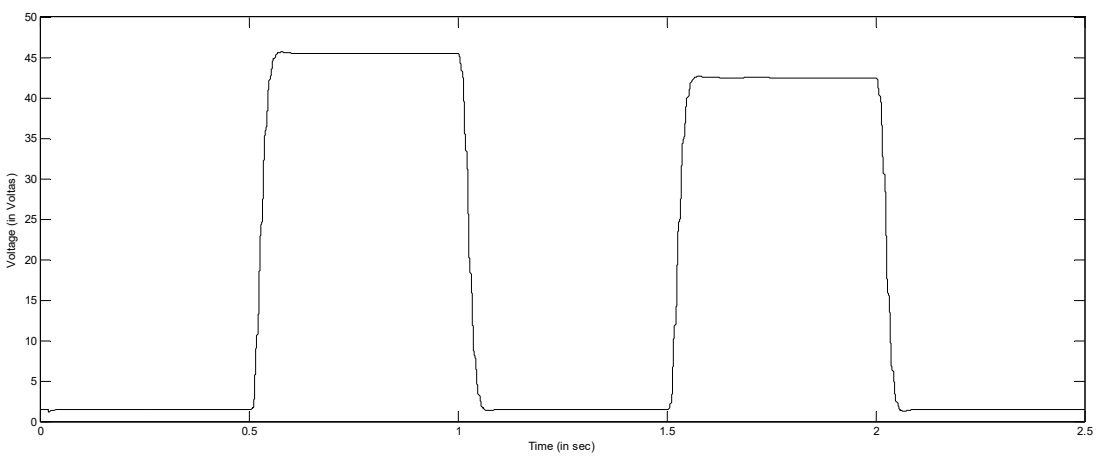

Figure 12. RMS value of ES voltage

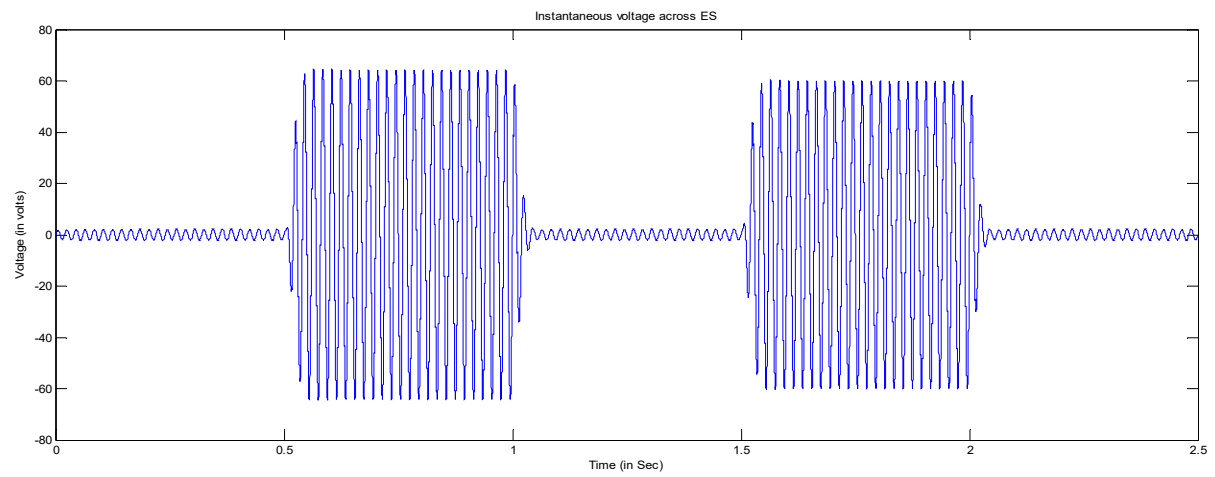

Figure 13. Instantaneous voltage of ES

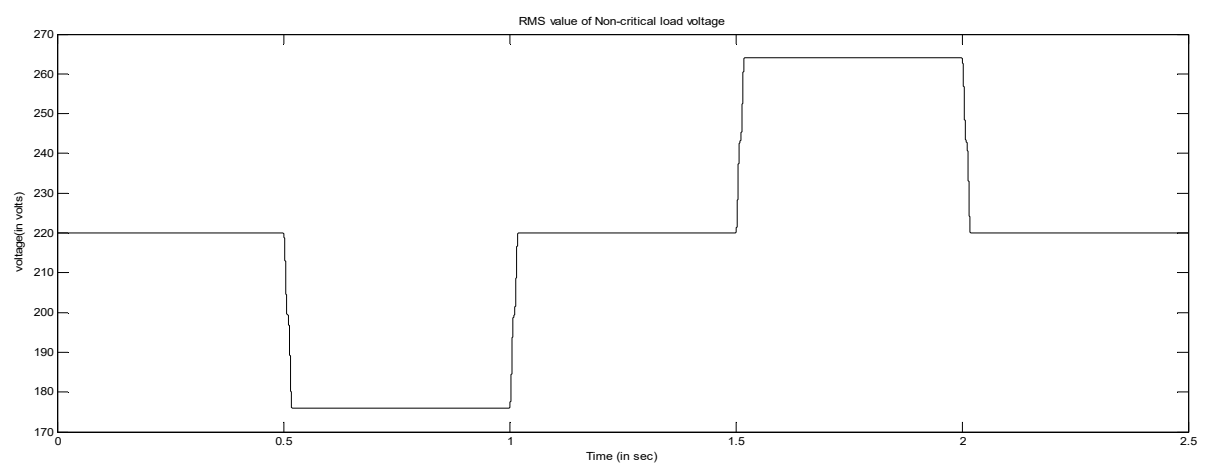

Figure 14. RMS value of non-critical load voltage

Voltage unbalancing is one of the problems in multilevel inverter, which occurs due to stress in electric devices. This is mainly due to the continuous operation of the DC link capacitor connected across the voltage source. This problem of voltage unbalance in the simulated multilevel inverter is reduced using a voltage balancing device called as resonant switching capacitor converter (RSCC). Voltage balancing achieved across the 3 capacitors of the MLI, is shown in Figure 15. It can be observed that the voltage is maintained nearly equal to $133.3 \mathrm{~V}$ across each input capacitor. Hence this justifies that the voltage balancing is achieved in the multi-level inverter circuit by RSCC. Sinusoidal PWM (SPWM) technique is used to generate the pulses to the switches of MLI. Figure 16 and Figure 17 describe the THD of the line voltage in sag and swell conditions respectively calculated by FFT. $0.44 \%$ THD in undervoltage as well as overvoltage

Int J Pow Elec \& Dri Syst, Vol. 11, No. 2, June 2020 : $555-565$ 
conditions corroborates the effectiveness of MLI in all the 3 modes of operation of ES. Comparison of $\mathrm{THD} \%$ amongst various inverter topologies for ES control is shown in Figure 18.

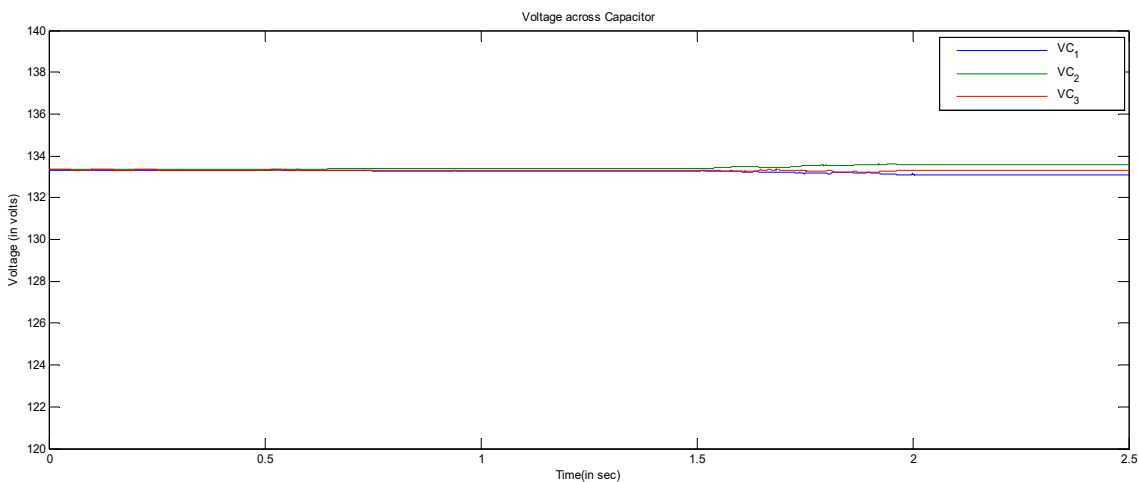

Figure 15. Voltage across capacitors in MLI

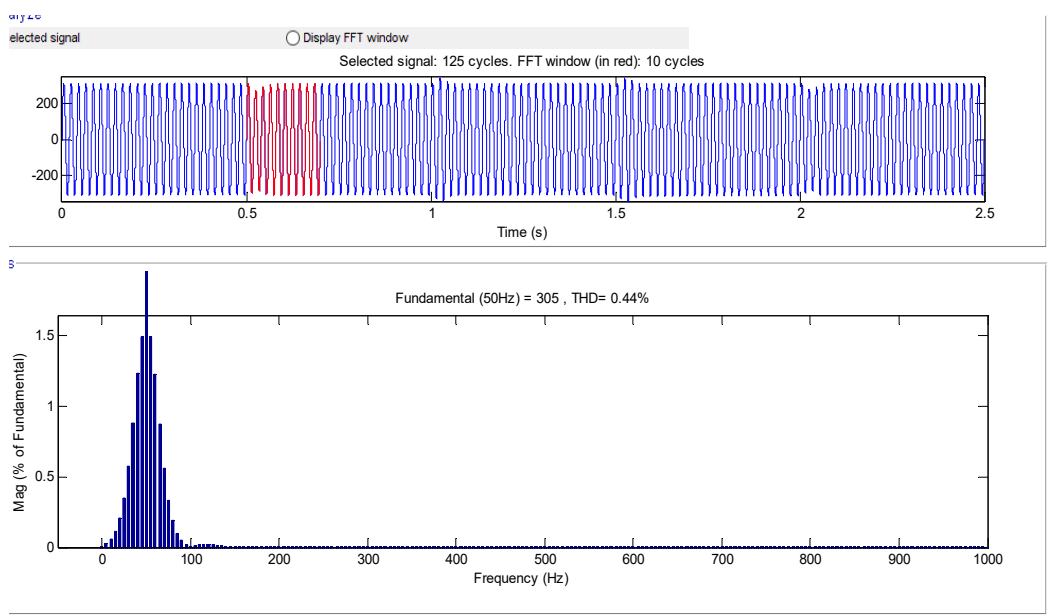

Figure 16. FFT Analysis of line voltage under voltage sag condition

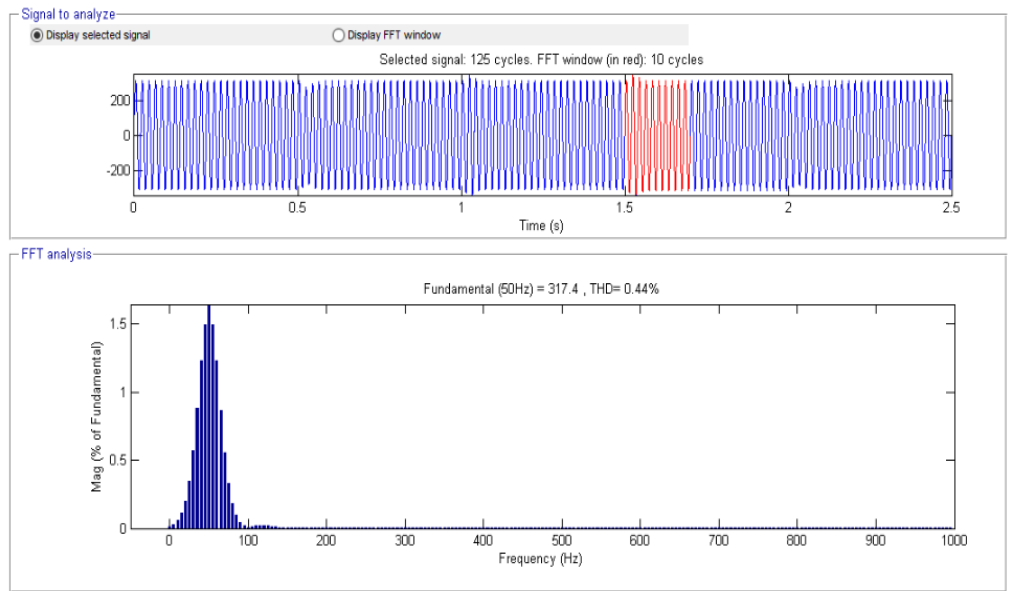

Figure 17. FFT Analysis of line voltage under voltage swell condition 


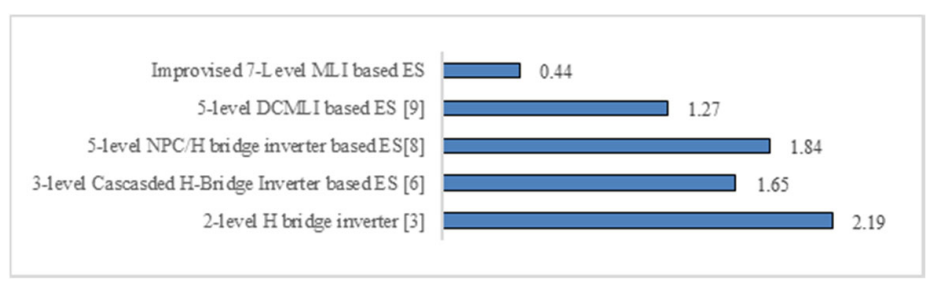

Figure 18. Comparison of THD\% amongst various inverter topologies for ES control

\section{CONCLUSION}

Voltage regulation for critical load with 7-level Inverter based Electric Spring is proposed and analysed in this paper. An overall review on the performance of Multilevel Inverter is analysed for various output voltage levels, also highlighting the voltage balancing achieved with Resonant Switching Capacitor Converter. Any distribution system with fluctuating renewable energy sources, when operated with Electric spring will regulate the critical load voltage effectively under the resulting voltage sag and swell conditions. Implementation of the 7-level inverter reduced the harmonics in the output voltage limiting the number of power switches. Simulations have been done on distribution system with DGs equipped with MLI based ES under line voltage anomalies. Tested results are analyzed with THD \% in critical load voltage.

\section{REFERENCES}

[1] RS Ravi Sankar, SV Jaya Kumar, KK Deepika, "Model Predictive Current Control of Grid Connected PV System", Indonesian Journal of Electrical Engineering and Computer Science (IJEECS), Vol. 2, No. 2.pp285-296, 2016.

[2] Yoshinaga, J., Akagi, S., Ito, M., Hayashi, Y., Ishibashi, K., \& Takahasi, N. "Voltage fluctuation issue on distribution system at time of demand response and cooperating voltage control method between battery energy storage system and SVR.” IEEJ Transactions on Power and Energy, Vol. 136, No. 4, pp. 400-409, 2016.

[3] S. Santoso, R. Dugan, M. F. McGranaghan, and H. W. Beaty, Electrical Power Systems Quality, 3rd ed. New York, NY, USA: McGraw-Hill, 2012. 4 R. E. Fehr, "Power quality," in Industrial Power Distribution. Hoboken, NJ, USA: Wiley, 2016.

[4] R. E. Fehr, "Power quality," in Industrial Power Distribution. Hoboken, NJ, USA: Wiley, 2016.

[5] A. J. Roscoe and G. Ault, "Supporting high penetrations of renewable generation via implementation of real-time electricity pricing and demand response," IET Renewable Power Generation, Vol. 4, No. 4, pp.369-382, 2010.

[6] C. K. Lee, S. N. Li, and S. Y. R. Hui, "A design methodology for smart lighting systems powered by weakly regulated renewable power girds," IEEE Transactions on Smart Grid, Vol. 2, No. 3, pp. 548-554, Sep. 2011

[7] P. Palensky and D. Dietrich, "Demand side management: Demand response, intelligent energy systems, and smart loads," IEEE Trans. Ind.Informatics, vol. 7, no. 3, pp. 381-388, 2011.

[8] Q. Wang, M. Cheng, Y. Jiang, W. Zuo and G. Buja, "A Simple Active and Reactive Power Control for Applications of Single-Phase Electric Springs," in IEEE Transactions on Industrial Electronics, Vol. 65, No. 8, pp. 6291-6300, Aug. 2018.

[9] S.Y.R.Hui, C.K.Lee, Fu, "Electric springs-A new smart grid technology," IEEE Trans. Smart Grid, Vol. 3, No. 3, September. 2012, pp: 1552-1561.

[10] Tan, Siew-Chong \& Lee, Chi Kwan \& Hui, S.Y. "General Steady-State Analysis and Control Principle of Electric Springs with Active and Reactive Power Compensations." Power Electronics, IEEE Transactions on. Vol. 28, pp. 3958-3969, 2013. 10.1109/TPEL.2012.2227823.

[11] Soni, Jayantika \& Panda, Sanjib. "Electric Spring for Voltage and Power Stability and Power Factor Correction." IEEE Transactions on Industry Applications. pp. 1-1, 2017. 10.1109/TIA.2017.2681971.

[12] Deepika K, Vijayakumar J, G K Rao, Chaitanya S, "Adaptive PI control of Electric Springs for Voltage Regulation under Dynamic Load Changes", International Journal of Innovative Technology and Exploring Engineering, Vol, 8 No. 10, pp. 1051-1056, 2019.

[13] Jih-Sheng Lai and Fang Zheng Peng, "Multilevel converters-a new breed of power converters," in IEEE Transactions on Industry Applications, vol. 32, no. 3, pp. 509-517, May-June 1996. doi: 10.1109/28.502161

[14] Chaudhuri NR, Lee CK, Balarko Chaudhuri, "Dynamic modeling of electric springs" IEEE Transactions on Smart Grid, Vol. 5, No.5, Sept. pp:2450-8, 2014.

[15] Hasabelrasul, Hashim \& Yan, Xiangwu. "Comparison of Multicarrier PWM Techniques for Cascaded H-Bridge Multilevel Inverter." International Journal of Power Electronics and Drive Systems (IJPEDS). Vol, 8, No. 2, pp. 861-868, 2017.

[16] Madhusudana Reddy, B \& Reddy, Y \& Vijaya Kumar, M. "Modeling and simulation of 127 level optimal multilevel inverter with lower number of switches and minimum THD." International Journal of Power Electronics and Drive Systems (IJPEDS). Vol. 9, No. 4, pp. 1765-1773, 2018.

[17] Chetna Jangade, Kalyani Gajbhiye, Pavan Fuke, Payal Dahiwale,Samruddhi Bharati, Tina Patil, S.P.Gawande, "Voltage regulation and droop control of Electric spring using single phase cascaded H-bridge inverter for

Int J Pow Elec \& Dri Syst, Vol. 11, No. 2, June 2020 : 555 - 565 
stabilizing smart grid”, Journal of Research in Engineering and Applied Sciences. Vol. 2, Issue 2, pp-69-75, April 2017.

[18] Rutuja Pawar, S. P. Gawande, S. G. Kadwane, M. A. Waghmare, R. N. Nagpure "Five-Level Diode Clamped Multilevel Inverter (DCMLI) Based Electric Spring for Smart Grid Applications", Energy Procedia, Vol. 117, pp. 862-869, 2017.

[19] K. Gajbhiye, P. Dahiwale, S. Bharti, R. Pawar, S. P. Gawande and S. G. Kadwane, "Five-level NPC/H-bridge MLI based electric spring for harmonic reduction and voltage regulation," 2017 International Conference on Smart grids, Power and Advanced Control Engineering (ICSPACE), Bangalore, pp. 203-208, 2017.

[20] Shalchi Alishah, Rasoul \& Hosseini, Hossein. "A New Multilevel Inverter Structure for High-Power Applications using Multi-carrier PWM Switching Strategy.” International Journal of Power Electronics and Drive Systems (IJPEDS), Vol. 6, No. 2. pp. 318-325, 2015.

[21] K. Narasimha Raju M .Venu Gopala Rao M.Ramamoorthy, "Hybrid Modulation Technique for Neutral Point Clamped Inverter to eliminate neutral point shift with minimum switching loss" TENCON 2015.

[22] K. W. E. Cheng, "New generation of switched capacitor converters," PESC 98 Record. 29th Annual IEEE Power Electronics Specialists Conference (Cat. No.98CH36196), Fukuoka, 1998, pp. 1529-1535 vol.2.

[23] K. Sano and H. Fujita, "Voltage-Balancing Circuit Based on a Resonant Switched-Capacitor Converter for Multilevel Inverters," in IEEE Transactions on Industry Applications, vol. 44, no. 6, pp. 1768-1776, Nov.-dec. 2008.

[24] C. Hsieh, T. Liang, S. Chen and S. Tsai, "Design and Implementation of a Novel Multilevel DC-AC Inverter," in IEEE Transactions on Industry Applications, vol. 52, no. 3, pp. 2436-2443, May-June 2016. doi: 10.1109/TIA.2016.2527622.

[25] Mulyo Utomo, Wahyu \& Bakar, Afarulrazi \& Alias, Suhaila \& Sy Yi, Sim \& Setiawan, Muhammad \& Mudjanarko, Wiwoho \& Sukoco, Agus \& Buswig, Yonis.m.Yonis \& Taufik, Taufik. "Modeling of A Single Phase 7-Level Cascaded H-Bridge Multilevel Inverter." International Journal of Engineering \& Technology, Vol. 7, No. 1. pp. 327-330, 2018.

\section{BIOGRAPHIES OF AUTHORS}

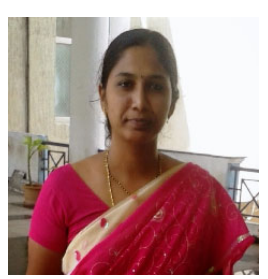

K.K.Deepika received her B.Tech. degree in Electrical and Electronics Engineering from Bapatla Engineering College, Guntur. She received her M.Tech. degree in Power Systems and Automation from GITAM University. She is currently pursuing her Ph. D. degree in Electrical Engineering at KLEF, Vijayawada, Andhra Pradesh, India. She is working as Assistant Professor in the Department of EEE in Vignan's Institute of Information Technology, Visakhapatnam, Andhra Pradesh, India. Her research interests include Distribution Systems, Renewable energy Sources and Demand Side Management.

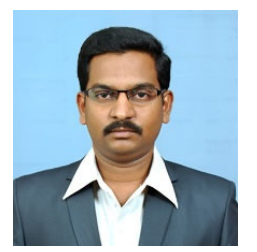

Dr. J.Vijaya Kumar received B. Tech. from J. N. T. U Kakinada in 2002, M.Tech. from Maulana Azad National Institute of Technology (MANIT) Bhopal in 2005 and Ph.D. degree in Electrical Engineering from National Institute of Technology (NIT), Warangal. He is working as Professor in the Department of EEE in ANITS, Visakhapatnam, Andhra Pradesh, India. His current research interests include power system deregulation and artificial intelligence technique applications in power systems. 